\title{
Spontaneous response to and expressive regulation of mirth elicited by humorous cartoons in younger and older adults
}

\author{
Sandrine Vieillard and Charlotte Pinabiaux \\ Laboratoire CHArt-Upon, EA4004, Université Paris Nanterre, Nanterre, France
}

\begin{abstract}
Many studies have examined the effect of aging on the ability to regulate negative emotions but less is known about the way the elderly people control their positive affects. Thirty-eight younger and 38 older adults were compared on their affective, expressive, physiological, and behavioral spontaneous responses to and in expressive regulation of mirth elicited by humorous cartoons. Compared to younger adults, older adults were equally amused and aroused but showed lower expressivity in their spontaneous reaction. They were similarly successful in implementing expressive regulation but they had lower physiological activation under amplification condition and more gaze avoidance from the key areas of the cartoons under suppression condition. This indicates that in older, amplification skills are disjointed from the physiological responses and suppression skills seem supplanted by a less costly strategy of attention redeployment. This also suggests that older adults' behavior is not driven by a greater preference for positive information.
\end{abstract}

\author{
KEYWORDS \\ Humorous stimuli; emotion \\ regulation; physiological \\ responses; gaze behavior; \\ positivity bias
}

Several studies have consistently shown that older adults reported having higher levels of well-being and experiencing more positive emotions than younger adults (Carstensen et al., 2011; Charles, Reynolds, \& Gatz, 2001; Consedine \& Magai, 2006; Gross et al., 1997; Lawton, 2001; Mroczek \& Kolarz, 1998). Other findings have demonstrated that, compared to their younger counterparts, older adults preferentially attend to and remember positive information over negative information (e.g., Mather \& Carstensen, 2005). This robust empirical phenomenon, called the positivity effect (e.g., Reed \& Carstensen, 2012; Reed, Chan, \& Mikels, 2014), has been explained by the Socio-emotional Selectivity Theory (SST, Charles \& Carstensen, 2009). According to this model, the positive developmental trajectory observed in aging is the result of motivational changes. Because older adults are acutely aware of their limited perspective of time, they would be more focused than younger adults on emotionally meaningful goals such as the search for positive emotions. Importantly, the SST postulates that the positivity effect would serve an emotion regulatory function. As a result, this theoretical model predicts that older adults would be more inclined to use emotion regulation strategies to maximize positive emotions.These strategies are collectively defined as the ability to monitor which emotions we have, when we 
have them, and how we experience and express them (Gross \& Thompson, 2007). Importantly, the notion of emotion regulation encompasses the possibilities of reducing, maintaining or increasing any affect, including positive emotions (Gross, 2014).

Many studies have been conducted to test this hypothesis, primarily focusing on the ability to regulate negative basic emotions such as anger (Magai, Consedine, Krivoshekova, Kudadjie-Gyamfi, \& McPherson, 2006), disgust (Kunzmann, Kupperbusch, \& Levenson, 2005; Shiota \& Levenson, 2009), or sadness (Magai et al., 2006; Shiota \& Levenson, 2009), moral emotion such as injustice (Phillips, Henry, Hosie, \& Milne, 2008) or even negatively valenced emotions operationalized along the two psychological dimensions of pleasantness and arousal (Opitz, Rauch, Terry, \& Urry, 2012; Vieillard, Harm, \& Bigand, 2015; Winecoff, Labar, Madden, Cabeza, \& Huettel, 2011). The available data depicted different age-related effects depending on the nature of the emotion regulation strategy. While older adults show preserved abilities to implement expressive suppression (Kunzmann et al., 2005; Magai et al., 2006; Phillips et al., 2008; Shiota \& Levenson, 2009; Vieillard et al., 2015), findings indicated that they had sometimes more difficulties to decrease unpleasant emotions through some reappraisal strategies (Opitz et al., 2012; Shiota \& Levenson, 2009). More exactly, Shiota and Levenson (2009) demonstrated that, in comparison with younger adults, older adults were better at implementing positive reappraisal but showed a decreased ability to implement detached reappraisal. Additional findings have given evidence that older adults' reappraisal efficiency was related to their cognitive preservation (Winecoff et al., 2011).

However, most of the above studies have been conducted on visual stimuli with no control for gaze direction. The exploration of gaze direction is an important cue to address age-related differences in emotion regulation strategy. Indeed, the possibility that visual attentional deployment might explain the successful expressive regulation previously found in older adults cannot be excluded. The only study that controlled gaze direction in an expressive regulation task confirmed this suspicion showing that, compared to their younger counterparts, older adults displayed more gaze aversion from visual stimuli conveying injustice under expressive suppression instructions (Phillips et al., 2008). This suggests that older adults might use a less costly regulation strategy of avoidance to regulate their negative emotions. Avoidance strategy indeed requires less use of cognitive resources than other emotion regulation strategies, such as reappraisal. This has been corroborated by a recent work on cognitive regulation indicating that when instructed to reappraise the affective meaning of their emotional state induced by negative pictures, older adults were more likely than their younger counterparts to shift their attention from negative visual stimuli (Opitz et al., 2012). This advocates the idea that the older adults' preservation of emotion regulation abilities could sometimes be explained by an age-related change in the preferential emotion regulation strategies like attentional deployment (Gross, 2014). Therefore, attention deployment may have a greater impact on emotional regulation success in aging than more costly strategies such as expressive or cognitive regulation. More generally, this suggests that age-related changes in regulation of negative expression and emotion perhaps are not always synonymous for more efficiency. This calls for a systematic control of gaze direction in empirical works investigating emotion regulation in response to visual stimuli. 
As mentioned above, the SST model argued that aging is characterized by the intentional use of emotion regulation strategies to favor positive emotions. This model postulates that age-related differences in emotion regulation are the consequences of the older adults' preference for positive stimuli over negative stimuli (Reed \& Carstensen, 2012; Reed et al., 2014). Literature have shown that sometimes the positivity effect is observed through a positivity bias that is the preference for positive information relative to neutral information among older adults in comparison with younger adults (e.g., Mather et al., 2004; Mikels, Larkin, Reuter-Lorenz, \& Carstensen, 2005), other times it is mirrored in a reduced preference for negative information relative to neutral information among older adults in comparison with younger adults (Charles, Mather, \& Carstensen, 2003; Vieillard \& Bigand, 2014). In this study, one of our goals was to verify whether positivity bias in older adults might influence how they spontaneously respond to positive stimuli like humor and how they regulate their expression of mirth. Recent findings have demonstrated that when instructed to perform an emotion regulation strategy choice paradigm, older adults did not favor distraction strategy over reappraisal strategy in regulating their positive emotion in comparison with their younger counterparts. Actually, it has been shown that older men chose to distract less from positive images than younger men did (Martins, Sheppes, Gross, \& Mather, 2016). But to date, no cross-sectional study on the more cognitively and physiologically costly strategy of the expressive regulation (Gross, 2014) has been conducted. To our knowledge, the only empirical work addressing the consequences of expressive regulation of humorous stimuli was based on a comparison between a group of Alzheimer's disease patients and a control group of older adults (Henry, Rendell, Scicluna, Jackson, \& Phillips, 2009). These findings showed that the subjective experience of humor and the ability to inhibit ongoing expression were relatively similar across groups. However, these data did not provide information on the age-related differences in the affective, expressive, physiological, and gaze behavior consequences or expressive regulation.

Among positive emotions, the feeling of mirth, described as the emotion resulting from a humorous appraisal of a situation or a joke (see Martin, 2007 for a review), is considered to be an important factor in everyday well-being as well as an efficient form of intrinsic (Samson \& Gross, 2012) and extrinsic (Harm, Vieillard, \& Didierjean, 2014; Strick, Holland, Van Baaren, \& Van Knippenberg, 2009) emotion regulation. Older adults have been observed to have preserved emotional responses to humor and used it as an efficient coping strategy (Harm et al., 2014; Shammi \& Stuss, 2003). Further, previous studies have shown that the ability to regulate mirth can be assessed experimentally (Giuliani, McRae, \& Gross, 2008; Henry et al., 2009). For instance, Giuliani et al. (2008) asked young adults to reappraise positively and negatively the emotion of mirth they felt while watching short humorous movies. They observed that participants successfully used reappraisal to amplify and diminish their affective (self-assessed feelings), behavioral (facial expression) and physiological (i.e., heart rate (HR), blood pressure, and skin conductance) responses. To date and to our knowledge, no previous work has investigated the older adults' abilities to enhance and inhibit the expression of positive emotions like amusement. 


\section{Current study}

The goal of the present study is to observe whether aging has an impact on the spontaneous response to humorous cartoons as well as on the ability to amplify and suppress the emotional expression of mirth. To this purpose, we used three blocks of humorous cartoons previously controlled to be equally funny for the young and the elderly (Harm et al., 2014). Participants were instructed to watch each block of cartoons with a specific instruction: simply watch, exaggerate, or inhibit the expression of amusement. Emotional responses to cartoons were assessed through the self-rating of amusement, facial expressivity, physiological activation, and gaze behavior. The control of gaze direction appears especially important to investigate the actual strategies used by the individuals under the different conditions.

\section{Hypotheses of the study}

Regarding the theoretical framework of the SST model described earlier, we can expect that positive emotions elicited by the humorous cartoons could be potentiated in older adults compared with their younger counterparts, resulting in a positivity bias in the "simply watch" condition. But taking into account previous findings showing that spontaneous facial expressivity is spared from age-related decline (see Fölster, Hess, \& Werheid, 2014 for a review), we specifically hypothesized that, compared to younger adults, older adults would be equally expressive under the condition of spontaneous response to humor. In the condition of expressive regulation, the hypothesis of a positivity bias in the elderly leads to predicted that, compared to younger adults, older people would be more responsive to positive material and would be more efficient at amplifying their positive feeling and expression. In addition, in line with findings indicating that older adults preferentially used an attentional deployment strategy to down-regulate their emotional expression (Phillips et al., 2008), it can be expected that under the suppression instruction older adults would achieve expressive inhibition by using the less costly strategy of avoidance. This assumption is also in agreement with the literature indicating less efficient inhibitory processes in the elderly (Hasher \& Zacks, 1988). More especially, we hypothesized that compared to younger adults, older adults would show more gaze aversion from the humorous area of the cartoons. On the other hand, if older adults preferentially process positive stimuli (i.e., positivity bias), they should have more difficulty in disengaging their attention from the key areas of the humorous cartoons.

Consequently, they should be less efficient at implementing suppressive expression than their younger counterparts.

\section{Method}

\section{Participants}

We recruited participants in from two age groups: 38 younger adults aged from 19 to 40 years old $(M=26, S D=7)$ and 38 older adults aged from 50 to 78 years old $(M=62$, $S D=8$ ) through written and online advertisement in Besançon (France). All participants were volunteers and were paid for their participation. We ensured that participants had no neurological or psychiatric antecedent and reported normal or corrected visual acuity. As illustrated in Table 1, older adults reported lower general health than younger adults. The 
Table 1. Sample characteristics.

\begin{tabular}{|c|c|c|c|c|}
\hline & $\begin{array}{l}\text { Younger Adults } \\
\quad(n=36)\end{array}$ & $\begin{array}{l}\text { Older Adults } \\
\quad(n=36)\end{array}$ & $\begin{array}{l}\text { Levene's } \\
\text { homogeneity test }\end{array}$ & $\begin{array}{l}\text { Age Group } \\
\text { Differences }\end{array}$ \\
\hline & Mean & Mean & $p$ value & $p$ Value ${ }^{(\mathrm{a}, \mathrm{b})}$ \\
\hline \multicolumn{5}{|l|}{ Demographic } \\
\hline Age (years) & $26(7)$ & $63(8)$ & 0.27 & $0.00^{a}$ \\
\hline Education (years) & $14.81(2.05)$ & $14.25(3.20)$ & 0.04 & $0.45^{b}$ \\
\hline Self-reported health (max. 5) & $4.46(0.84)$ & $3.90(0.66)$ & 0.43 & $0.00^{a}$ \\
\hline \multicolumn{5}{|l|}{ Cognitive functioning } \\
\hline Mini Mental State Examination (MMSE) & - & $29.5(0.69)$ & - & \\
\hline Flexibility: Trail Making Test (s) & $35.10(56.57)$ & $51.63(28.44)$ & 0.72 & $0.12^{a}$ \\
\hline $\begin{array}{l}\text { Fluid Intelligence: Advanced Progressive } \\
\text { Matrices (Set 1, max. 12) }\end{array}$ & $10.11(1.69)$ & $9(2.28)$ & 0.22 & $0.02^{a}$ \\
\hline Inhibition: Victoria Stroop (IF) & $1.86(0.51)$ & $2.31(0.78)$ & 0.45 & $0.00^{a}$ \\
\hline $\begin{array}{l}\text { Working Memory: Letter-Number } \\
\text { Sequencing (max. 21) }\end{array}$ & $13.83(3.47)$ & $10.75(2.63)$ & 0.03 & $0.00^{\mathrm{b}}$ \\
\hline \multicolumn{5}{|l|}{ Affective functioning } \\
\hline BDI-II (max. 63) & $6.45(4.90)$ & $7.58(5.83)$ & 0.53 & $0.36^{a}$ \\
\hline STAI-Y Anxiety State (max. 80) & $30(8.51)$ & $28.81(7.98)$ & 0.38 & $0.54^{a}$ \\
\hline STAI-Y Anxiety Trait (max. 80) & $37.67(7.54)$ & $38.03(6.87)$ & 0.43 & $0.83^{a}$ \\
\hline PANAS Positive Affect (max. 50) & $34.31(5.09)$ & $33.97(6.19)$ & 0.43 & $0.80^{a}$ \\
\hline PANAS Negative Affect (max. 50) & $16.5(4.39)$ & $17.94(6.09)$ & 0.38 & $0.25^{a}$ \\
\hline ERQ Suppression (max. 28) & $13.58(5.61)$ & $13.75(5.37)$ & 0.52 & $0.90^{a}$ \\
\hline ERQ Reappraisal (max. 42) & $26.75(7.44)$ & $27.47(8.20)$ & 0.37 & $0.70^{a}$ \\
\hline BEQ Positive Expressivity (max. 7) & $5.51(0.95)$ & $5.28(1.10)$ & 0.62 & $0.33^{a}$ \\
\hline BEQ Negative Expressivity (max. 7) & $3.98(0.96)$ & $4.20(1.00)$ & 0.99 & $0.35^{a}$ \\
\hline BEQ Global Expressivity (max. 7) & $4.68(0.85)$ & $4.82(0.82)$ & 0.94 & $0.46^{a}$ \\
\hline \multicolumn{5}{|l|}{ Personality trait } \\
\hline NEO-PI-R neuroticism score (max. 192) & $87.97(17.77)$ & $85.86(19.42)$ & 0.83 & $0.63^{a}$ \\
\hline NEO-PI-R extraversion score (max. 192) & $113.83(20.21)$ & $103.86(15.84)$ & 0.09 & $0.02^{a}$ \\
\hline NEO-PI-R openness score (max. 192) & $122.36(15.19)$ & $115.14(17.45)$ & 0.62 & $0.07^{a}$ \\
\hline NEO-PI-R agreeableness score (max. 192) & $120.39(20.81)$ & $128.89(13.11)$ & 0.02 & $0.10^{b}$ \\
\hline NEO-PI-R conscientiousness score (max. 192) & $111.92(21.08)$ & $120.77(19.10)$ & 0.31 & $0.07^{a}$ \\
\hline \multicolumn{5}{|l|}{ Ratings } \\
\hline \multicolumn{5}{|l|}{ Humorous cartoons } \\
\hline Understanding (max. 9) & $7.18(1.08)$ & $6.66(1.08)$ & 0.98 & $0.04^{a}$ \\
\hline Funniness (max. 9) & $5.46(1.85)$ & $5.43(1.54)$ & 0.06 & $0.94^{a}$ \\
\hline Valence (max. 9) & $4.23(1.61)$ & $4.15(1.8)$ & 0.45 & $0.86^{a}$ \\
\hline \multicolumn{5}{|l|}{ Neutral cartoons } \\
\hline Understanding (max. 9) & $8.12(1.23)$ & $5.59(2.67)$ & 0.00 & $0.00^{b}$ \\
\hline Funniness (max. 9) & $0.84(1.38)$ & $1.77(1.87)$ & 0.03 & $0.03^{b}$ \\
\hline Valence (max. 9) & $5.08(1.75)$ & $5.01(2.19)$ & 0.27 & $0.87^{a}$ \\
\hline
\end{tabular}

Notes. Standard deviations are listed in parantheses; ERQ, Emotion Regulation Questionnaire; PANAS, Positive and Negative Affect Schedule; NEO-PI-R, Revised NEO Personality Inventory; BEQ, Berkeley Expressivity Questionnaire. Number of years of education has been calculated from 6 years old (age at which school is compulsory in France). ${ }^{a}$ Comparisons were assessed by $t$-tests.

${ }^{\mathrm{b}}$ Comparisons were assessed by Mann-Whitney's U-test.

Mini-Mental Status Examination (MMSE, Folstein, Folstein \& McHugh, 1975) was used to exclude older participants with possible dementia (MMSE < 27). The State-Trait Anxiety Inventory (STAI-Y, Spielberger, Gorsuch, Lushene, Vagg \& Jacobs, 1983) and the Beck Depression Inventory (BDI-II, Beck, Steer, Ball \& Ranieri, 1996) were used to exclude the participants with anxiety disorders or depression, respectively; when the scores obtained by the participants were greater than the cut-off as explicated in the manual of the inventories (STAI-Y standard scores > 55; BDI-II raw scores $>27$ ), those participants were excluded. Four volunteers (two younger adults and two older adults) were excluded due to high STAI-Y scores. No statistically significant difference was observed between age groups 
for the measures of anxiety and depression. The participants were also controlled for their emotion regulation styles (Emotion Regulation Questionnaire, ERQ, Gross \& John, 2003), their current feeling (Positive And Negative Affectivity Scale, PANAS-X, Watson \& Clark, 1994), and their expressivity expressivity (Berkeley Expressivity Questionnaire, BEQ, Gross \& John, 1997). No statistically significant difference was observed between age groups for these additional affective measures. Compared to younger adults, we found that older adults showed lower scores in cognitive tasks involving working memory (Letter-Number Sequencing subtest of the WAIS-III, Wechsler, 1997), inhibition inhibition (IF score of the Victoria Stroop test, Tremblay et al., 2016) and fluid intelligence (Advanced Progressive Matrices, APM, Set 1, Raven, Raven \& Court, 2003) performances. No statistically significant difference between age groups was found concerning the cognitive flexibility (Trail Making Test, Tombaugh, 2004). In line with previous findings on age-related changes in personality (e.g., Terracciano, McCrae, Brant \& Costa, 2005), the examination of personality trait (measured by the French validation of NEO-P-IR by Plaisant et al., 2010) showed agerelated decline on the mean scores of Extraversion. No other significant difference was found.

\section{Materials}

Twelve humorous and three neutral cartoons were used in this experiment. All of these cartoons displayed a black and white drawing with a caption. The neutral cartoons depicted non-emotional social situations (e.g., two children in a library) while the humorous cartoons were taken from drawings by Gary Larson $(1985,1987,1988)$ ) previously used by Schmidt (2002) and controlled for their mirth elicitation with younger and older adults in a previous study (Harm et al., 2014). The 12 humorous cartoons were divided into 3 blocks of 4 cartoons within which the order of presentation was randomized. Each block was assigned to a specific instruction of emotion regulation (i.e., simply watch, expressive amplification, or expressive suppression) with a counterbalancing across participants. Five additional humorous black and white drawing without captions were selected for training. At the end of the experiment, participants were asked to rate humorous and neutral cartoons on 10-point scales to judge whether they were understandable (with 0 meaning "pas du tout"/not at all and 9 meaning, "tout à fait"/completely), funny (with 0 meaning "pas du tout"/not at all and 9 meaning, "tout à fait"/completely), and whether they had positive meaning (with 0 meaning "pas du tout"/not at all and 9 meaning, "tout à fait"/completely). For humorous cartoons, and as illustrated in Table 1, no statistically significant difference was found across age groups on funniness and valence ratings. However, older adults judged the humorous cartoons as less easy to understand than their younger counterparts. For neutral cartoons, no statistically significant difference was found across age groups on valence ratings. But older adults judged the neutral cartoons as less easy to understand and more funny than younger adults.

\section{Procedure}

The experiment was divided into two sessions separated by an interval of about one week. During the first session, participants were asked to sign a consent form as well as a demographic questionnaire including information about their age, education level, self-reported health, visual acuity, and medical history. They were then 
presented with a set of cognitive and affective tests. The first session lasted about 1 $\mathrm{h}$ and $\mathrm{a}$ half.

The second session included experimental task and lasted about $1 \mathrm{~h}$. Participants were tested individually in a quiet room at stable ambient temperature at the university of Franche-Comté. Once the participants were installed with the physiological and eye tracking systems, they were asked to watch five humorous pictures one by one in a set of training trials. These trials were used to familiarize participants with the expressive regulation instructions. During this training, they saw one picture with the simply watch instructions ("watch the cartoons in a natural way without controlling your expression of emotions"), two pictures with the instructions to amplify emotional expression ("try to express as much as possible your feeling of mirth so that someone looking at you would clearly know what you are feeling"), and two pictures with the instructions to suppress emotional expression ("try to not express your feeling of mirth so that someone looking at you would not know how you are feeling"). Then, the experimental trials started with one block of three neutral cartoons with the simply watch instructions followed by the three blocks of four humorous cartoons that were associated with one of the three instructions (i.e., simply watch, amplify and suppress) with counterbalancing across participants.

Each trial began after the emotion regulation instructions (i.e., simply watch, amplify or suppress) were reminded and after the participants indicated they were ready. A $10 \mathrm{~s}$ blank screen was displayed while physiological baseline was recorded, followed by a fixation cross of $1 \mathrm{~s}$ duration. Immediately after, the cartoon was displayed during $30 \mathrm{~s}$. At the end of the cartoon's display duration, participants had to assess orally on a 10point Likert scale to what extent they felt the emotion of mirth ("I am amused" from 0 "not at all" to 9 "entirely"). For each trial, the experimenter carefully scrutinized the Skin Conductance Level and initiated the next trial only when it had stabilized, making sure that measure did return to the baseline.

Once the expression regulation task was ended, the eye tracking and physiological systems were removed. As described earlier, participants were then asked to rate the cartoons previously presented on three 10-point Likert scales in order to assess to what extent they found the cartoons funny, understandable and conveying positive meaning. All participants were then debriefed and paid.

\section{Data acquisition and transformation}

Physiological responses were monitored throughout the experiment using an MP150 Biopac system (Biopac Systems, Inc., Goleta, CA) at a sampling rate of $500 \mathrm{~Hz}$ and were processed using AcqKnowledge software. Participants' facial expressivity was assessed through their zygomaticus electromyographical activity (Facial EMG, $\mu$ Volts) with two $4 \mathrm{~mm}$ shielded electrodes located on left zygomaticus muscle (see recommendations of Tassinary, Cacioppo \& Vanman, 2007 2007).The signal was rectified using the root mean square function of the software and then smoothed using a $50 \mathrm{~Hz}$ band stop filter. The EMG score was calculated by subtracting the EMG signal recorded during the second before the onset of the cartoon from the EMG signal (area under the curve per second) recorded during the $10 \mathrm{~s}$ duration of cartoon presentation. Due to technical problem, the data from one younger participant were excluded from the analysis. Skin conductance level 
( $\mathrm{SCL}, \mu$ Siemens) was recorded on the left index and little fingers with two electrodes filled with isotonic gel. The reported $\mathrm{SCL}$ score was calculated by subtracting the SCL signal recorded at the onset of the cartoons from the SCL recorded from the third second to the end of the cartoon presentation. Electrocardiogram (HR in bpm) activity was recorded with three $8 \mathrm{~mm}$ electrodes located at left wrist $(+)$, right wrist (-), and left ankle (ground). The signal was smoothed using a $50 \mathrm{~Hz}$ band stop filter. Systolic (SBP, in $\mathrm{mm} / \mathrm{Hg}$ ) and diastolic (DBP, in $\mathrm{mm} / \mathrm{Hg}$ ) blood pressure were measured with two inflatable finger cuffs at the left middle and ring fingers and recorded by a continuous non-invasive arterial pressure monitor (CNSystems, Medizintechnik AG, Graz, Austria). Two scores were derived from the $\mathrm{HR}$ and arterial blood pressure (SBP and DBP) data. The first score was a reactivity score corresponding to the difference between the mean signal (HR, DBP, or SBP) during the cartoons presentation and the mean signal of the preceding $10 \mathrm{~s}$. The recovery score was the difference between the mean signal during the cartoons presentation and the mean measure during the $10 \mathrm{~s}$ following the cartoons presentation. The distribution of each variable was examined to identify possible remaining outliers (mean $\pm 3 \mathrm{SD}$ ). Based on this criterion, about $1.8 \%$ of all measurements was excluded from the analyses. Due to technical problems, data from eight older participants and seven younger participants were excluded from the analysis.

Participants' eye movements were recorded with a Tobii T120 system (Tobii Technology AB, Danderyd, Sweden) at a sampling rate of $60 \mathrm{~Hz}$ and the stimuli presentation was managed by the E-prime software (Schneider, Eschman, \& Zuccolotto, 2002). Each fixation was defined from the eye movement data not exceeding an Eye $3.01 \mathrm{pixel} / \mathrm{s}$ threshold. Our analyses were focused on the duration of eye fixations on two different areas of interest for each cartoon: the captions and the pictures areas. Data from participants who had a number of excluded trials greater than $25 \%$ were discarded. Based on this criterion, data from one younger participant were excluded from analysis.

\section{Analyses}

The normality and homogeneity of variances were tested using Shapiro-Wilk and Levene's tests before the statistical analyses were applied. Results of these analyses are presented in the supplementary material section. T-tests and analysis of variance with age group as between-subject factor were applied for data showing a normal distribution and homogeneity of variance. Variables for which these conditions were not met were analyzed with non-parametric statistics using Kruskal-Wallis $H$-tests and Mann-Whitney $U$-tests for between-groups comparisons.

For each affective (self-reported mirth), expressive (facial EMG), physiological (i.e., $\mathrm{SCL}, \mathrm{HR}, \mathrm{DBP}$ and SBP) and gaze direction (duration of eyes fixations) measure, we verified age equivalence in reactivity to baseline condition by comparing the two age groups in their responses to the neutral cartoons under the watch instruction. We then tested the efficacy of the humorous stimuli as mirth elicitors for each age group separatly (one sample $t$-test, comparison of the differential score with $\mu=0$ ) and additional analyses were performed to test age-related differences in the reactivity to them. To this purpose, we computed a differential score by subtracting the measure 
obtained for neutral stimuli in the simply watch condition from the measure obtained for humorous stimuli in the simply watch condition. The effects of expressive regulation instructions on affective, expressive, physiological responses and gaze direction were examined for each age group separatly and additional analyses were performed to test age-related differences. Again, for each measure, a differential score was calculated to determine the amount of change in response to each expressive regulation instruction by substracting the measure obtained for humorous stimuli in the expressive regulation instruction (amplification versus suppression) from the measure obtained for humorous stimuli in the simply watch condition. Positive scores corresponded to relatively higher mirth/response in the expressive regulation instruction compared to the simply watch condition. On the opposite, negative scores corresponded to higher mirth/response in the simply watch condition compared to the expressive regulation instruction. To investigate the consistency between affective, expressive, physiological, and gaze responses to spontaneous responses to humorous cartoons under the different expressive regulation instructions, correlation analyses were computed separately for younger and older adults (see supplementary material). Finally, to explore the relation between age group differences in affective and cognitive functioning and spontaneous responses to humorous cartoons and expressive regulation instructions, we performed a set of partial correlation analyses while controlling for the effects of age (see supplementary material). These correlational analyses are aimed to identify potential confounding factors known to change with age and which may explain our results in another way than by an age-related effect. For each set of correlations, a Bonferroni correction was used to account for the inflated chance of a Type I error associated with conducting multiple correlations. To this end, we adjusted the a level from 0.05 to 0.05 divided by the number of comparisons. The results of these correlational analyses are presented as supplementary materiel.

Table 2. Age equivalence in baseline condition (neutral cartoons).

\begin{tabular}{|c|c|c|c|}
\hline & $\frac{\text { Younger Adults }}{\text { Mean }}$ & $\begin{array}{c}\text { Older Adults } \\
\text { Mean }\end{array}$ & $\begin{array}{c}\text { Age } \\
\text { Comparisons }^{p \text { Value }}{ }^{(\mathrm{a}, \mathrm{b})}\end{array}$ \\
\hline \multicolumn{4}{|l|}{ Affective responses } \\
\hline Self-reported mirth (max. 9) & $1.00(1.41)$ & $1.43(1.62)$ & $0.15^{b}$ \\
\hline \multicolumn{4}{|l|}{ Expressive responses } \\
\hline $\begin{array}{l}\text { Facial EMG zygomaticus major (area under the curve, } \mathrm{mV} \times \mathrm{s} \text { ) } \\
\text { Physiological responses }\end{array}$ & $0.0009(0.0012)$ & $0.0013(0.0020)$ & $0.45^{b}$ \\
\hline $\mathrm{SCL}(\mu \mathrm{S})$ & $-0.13(0.23)$ & $-0.07(0.12)$ & $0.12^{b}$ \\
\hline $\mathrm{HR}(\mathrm{bpm})$ reactivity & $-3.24(8.59)$ & $-2.35(3.51)$ & $0.61^{b}$ \\
\hline $\mathrm{SBP}(\mathrm{mmHg})$ reactivity & $-0.74(1.93)$ & $-0.57(1.74)$ & $0.02^{b}$ \\
\hline DBP $(\mathrm{mmHg})$ reactivity & $-0.77(1.99)$ & $-0.08(1.83)$ & $0.31^{b}$ \\
\hline $\mathrm{HR}(\mathrm{bpm})$ recovery & $-3.64(10.67)$ & $-2.50(7.05)$ & $0.66^{b}$ \\
\hline $\mathrm{SBP}(\mathrm{mmHg})$ recovery & $-1.06(2.44)$ & $-0.55(2.31)$ & $0.31^{a}$ \\
\hline $\begin{array}{l}\text { DBP }(\mathrm{mmHg}) \text { recovery } \\
\text { Gaze direction }\end{array}$ & $-1.20(2.70)$ & $-0.09(1.85)$ & $0.07^{b}$ \\
\hline Duration (s) of gaze fixations toward cartoons' picture & $25.16(2.79)$ & $23.25(5.37)$ & $0.12^{b}$ \\
\hline Duration (s) of gaze fixations toward cartoons' caption & $2.40(1.33)$ & $2.55(1.88)$ & $0.98^{b}$ \\
\hline
\end{tabular}

Notes. Standard deviations are listed in parentheses. EMG, Electromyogram; SCL, Skin Conductance Level; HR, Heart rate; SBP, Systolic Blood Pressure; DBP, Diastolic Blood Pressure.

${ }^{a}$ Comparisons were assessed by $t$-tests.

${ }^{\mathrm{b}}$ Comparisons were assessed by Mann-Whitney's U-test. 


\section{Results}

\section{Age equivalence in baseline reactivity levels (neutral cartoons)}

As shown in Table 2, no statistically significant effect of age group was found on affective (self-reported mirth), expressive (facial EMG), physiological (SCL, HR, DBP), or gaze direction (duration of eyes fixations) measures, except for SBP indicating that older adults showed higher SBP in reactivity period than the younger adults $(p=.019$, Mann-Whitney $U$ $=260$ ).

\section{Age-related effects on spontaneous responses to humor}

As illustrated in Table 3, the set of one sample t-tests $(\mu=0)$ applied on the two age groups separately indicated that younger and older adults reported to be amused by the humorous cartoons $(t(35)=9.55, p<.001$ in younger adults and $t(35)=9.21, p<.001$ in older adults), showed higher $\mathrm{SCL}$ for humorous cartoons, $(t(35)=2.70, p=.011$ in younger adults and $t(35)=2.37, p=.024$ in older adults), looked more toward humorous cartoons' caption, $(t(34)=7.77, p<.001$ in younger adults and $t(35)=7.23, p<.001$ in older adults), but less toward humorous cartoons' picture $(t(34)=-6.13, p<.001$ in younger adults and $t(35)=-4.84, p<.001$ in older adults). Younger but no older adults displayed greater EMG zygomaticus major activity $(t(34)=3.66, p<.001)$ and showed increased DBP in reactivity period $(t(27)=2.38, p=.023)$ for humorous cartoons. Age-related effect analyses indicated that the effect of humor on the EMG zygomaticus major activity was more pronounced in younger adults than in older adults $(p=.023$, Mann-Whitney $U=432$ ). No other statistically significant effect of age group was found.

Table 3. Spontaneous responses (differential scores) to humorous cartoons in younger and older adults.

\begin{tabular}{|c|c|c|c|}
\hline & \multirow{2}{*}{$\frac{\text { Younger Adults }}{\text { Mean }}$} & \multirow{2}{*}{$\frac{\text { Older Adults }}{\text { Mean }}$} & \multirow{2}{*}{$\frac{\text { Comparisons }}{p \text { Value }^{(\mathrm{a}, \mathrm{b})}}$} \\
\hline & & & \\
\hline \multicolumn{4}{|l|}{ Affective responses } \\
\hline Self-reported mirth (max. 9) & $3.30(2.07)^{* * *}$ & $3.20(2.06)^{* * *}$ & $0.84^{a}$ \\
\hline \multicolumn{4}{|l|}{ Expressive responses } \\
\hline Facial EMG zygomaticus major (area under the curve, $\mathrm{mV} \times \mathrm{s}$ ) & $0.0022(0.0036)^{* * *}$ & $0.0008(0.0028)$ & $0.02^{b}$ \\
\hline \multicolumn{4}{|c|}{ Physiological responses } \\
\hline $\mathrm{SCL}(\mu \mathrm{S})$ & $0.13(0.28)^{*}$ & $-0.05(0.14)^{*}$ & $0.42^{b}$ \\
\hline HR (bpm) reactivity & 3.66 (9.84) & $1.81(7.84)$ & $0.44^{a}$ \\
\hline $\mathrm{SBP}(\mathrm{mmHg})$ reactivity & $-0.68(2.53)$ & $-0.45(2.22)$ & $0.57^{b}$ \\
\hline $\mathrm{DBP}(\mathrm{mmHg})$ reactivity & $0.83(1.84)^{*}$ & $0.31(2.52)$ & $0.38^{a}$ \\
\hline $\mathrm{HR}(\mathrm{bpm})$ recovery & $1.74(13.76)$ & $2.09(7.80)$ & $0.77^{b}$ \\
\hline $\mathrm{SBP}(\mathrm{mmHg})$ recovery & $0.38(2.75)$ & $0.39(2.13)$ & $0.98^{a}$ \\
\hline $\mathrm{DBP}(\mathrm{mmHg})$ recovery & $-0.24(3.15)$ & $0.01(2.41)$ & $0.66^{b}$ \\
\hline \multicolumn{4}{|l|}{ Gaze direction } \\
\hline Duration (s) of gaze fixations toward cartoons' picture & $-2.49(2.40)^{* * *}$ & $-3.05(3.77)^{* * *}$ & $0.76^{b}$ \\
\hline Duration (s) of gaze fixations toward cartoons' caption & $1.99(1.52)^{* * *}$ & $1.98(1.64)^{* * *}$ & $0.98^{a}$ \\
\hline
\end{tabular}

Notes. Mean values are differential scores (humorous cartoons in simply watch condition minus neutral cartoons in simply watch condition). Standard deviations are listed in parentheses. EMG, electromyogram; SCL, skin conductance level; HR, heart rate; SBP, systolic blood pressure; DBP, diastolic blood pressure.

${ }^{a}$ Comparisons were assessed by $t$-tests.

${ }^{\mathrm{b}}$ Comparisons were assessed by Mann-Whitney's $U$-test.

${ }^{*}$ Differential score is significantly different from 0 at $p<.05 ;{ }^{* *}$ differential score is significantly different from 0 at $p<.001$. 


\section{Age-related effects on expressive regulation of mirth}

\section{Expressive amplification}

As shown in Table 4, the set of one sample t-tests $(\mu=0)$ indicated that younger as well as older adults displayed greater EMG zygomaticus major activity in expressive amplification condition with $(t(34)=3.86, p<.001)$ in younger adults and $(t(35)=2.99, p=.01)$ in older adults. Younger adults showed increased SBP recovery $(t(27)=3.67, p<.001)$ and HR recovery $(t(27)=2.41, p=.02)$ while older adults did not $(t(28)=.84, p=.41$ and $t$ $(28)=.35, p=.76$, respectively). Age group comparisons showed that the difference

Table 4. Differential scores of younger and older adults' affective, expressive, physiological, and gaze behavior responses under expressive amplification and suppression instructions.

\begin{tabular}{|c|c|c|c|c|c|c|}
\hline & \multicolumn{2}{|c|}{ Younger Adults } & \multicolumn{2}{|c|}{ Older Adults } & \multicolumn{2}{|c|}{ Age comparisons } \\
\hline & \multicolumn{2}{|c|}{ Mean } & \multicolumn{2}{|c|}{ Mean } & \multicolumn{2}{|c|}{$p$-Value ${ }^{(\mathrm{a}, \mathrm{b})}$} \\
\hline & Amplification & Suppression & Amplification & Suppression & Amplification & Suppression \\
\hline \multicolumn{7}{|l|}{$\begin{array}{l}\text { Affective } \\
\text { responses }\end{array}$} \\
\hline $\begin{array}{l}\text { Self-reported } \\
\text { mirth (max. 9) }\end{array}$ & $0.32(1.88)$ & $-0.33(1.40)$ & 0.04 (1.98) & $-0.06(2.11)$ & $0.68^{b}$ & $0.46^{b}$ \\
\hline \multicolumn{7}{|l|}{$\begin{array}{l}\text { Expressive } \\
\text { responses }\end{array}$} \\
\hline $\begin{array}{l}\text { Facial EMG } \\
\text { zygomaticus } \\
\text { major (area } \\
\text { under the } \\
\text { curve, } \mathrm{mV} \times \mathrm{s} \text { ) }\end{array}$ & $0.003(0.005)^{* * *}$ & $-0.002(0.05)^{*}$ & $0.002(0.005)^{*}$ & $-0.001(0.003)$ & $0.14^{\mathrm{b}}$ & $0.22^{b}$ \\
\hline \multicolumn{7}{|l|}{$\begin{array}{c}\text { Physiological } \\
\text { responses }\end{array}$} \\
\hline $\mathrm{SCL}(\mu \mathrm{S})$ & $0.07(0.28)$ & $-0.07(0.26)$ & $0.08(1.18)^{*}$ & $-0.03(0.12)$ & $0.87^{\mathrm{b}}$ & $0.42^{b}$ \\
\hline $\begin{array}{l}\mathrm{HR} \text { (bpm) } \\
\quad \text { reactivity }\end{array}$ & $2.63(8.60)$ & $-0.01(10.68)$ & $2.28(8.69)$ & $2.10(8.72)$ & $0.88^{\mathrm{a}}$ & $0.42^{b}$ \\
\hline $\begin{array}{l}\mathrm{SBP}(\mathrm{mmHg}) \\
\text { reactivity }\end{array}$ & $1.06(2.89)$ & $-0.02(2.44)$ & $-0.19(2.24)$ & $0.50(3.42)$ & $0.51^{\mathrm{a}}$ & $0.78^{a}$ \\
\hline $\begin{array}{l}\mathrm{DBP}(\mathrm{mmHg}) \\
\text { reactivity }\end{array}$ & $0.70(2.17)$ & $-0.02(1.82)$ & $0.91(2.59)$ & $0.46(2.20)$ & $0.74^{\mathrm{a}}$ & $0.37^{a}$ \\
\hline $\begin{array}{l}\mathrm{HR}(\mathrm{bpm}) \\
\text { recovery }\end{array}$ & $4.30(9.46)^{*}$ & $0.06(8.13)$ & $0.60(9.17)$ & $-1.83(7.68)$ & $0.14^{\mathrm{a}}$ & $0.37^{a}$ \\
\hline $\begin{array}{l}\mathrm{SBP}(\mathrm{mmHg}) \\
\text { recovery }\end{array}$ & $1.51(2.18)^{* * *}$ & $0.42(2.08)$ & $0.36(2.29)$ & $-0.46(2.12)$ & $0.06^{\mathrm{a}}$ & $0.12^{a}$ \\
\hline $\begin{array}{l}\mathrm{DBP}(\mathrm{mmHg}) \\
\text { recovery }\end{array}$ & $-0.21(2.93)$ & $-0.53(2.44)$ & $0.46(2.81)$ & $-0.09(2.96)$ & $0.38^{\mathrm{a}}$ & $0.09^{b}$ \\
\hline \multicolumn{7}{|l|}{ Gaze direction } \\
\hline $\begin{array}{l}\text { Duration (s) of } \\
\quad \text { gaze fixations } \\
\text { toward } \\
\text { cartoons' } \\
\text { picture }\end{array}$ & $-0.24(2.72)$ & $0.52(1.73)$ & $-0.71(3.28)$ & $1.56(4.12)^{*}$ & $0.20^{\mathrm{b}}$ & $0.08^{b}$ \\
\hline $\begin{array}{l}\text { Duration (s) of } \\
\text { gaze fixations } \\
\text { toward } \\
\text { cartoons' } \\
\text { caption }\end{array}$ & $0.08(1.61)$ & $-0.15(1.27)$ & $0.07(1.62)$ & $-0.67(1.56)^{*}$ & $0.98^{b}$ & $0.13^{a}$ \\
\hline
\end{tabular}

Mean values are differential scores (humorous cartoons in simply watch condition minus neutral cartoons in simply watch condition). Standard deviations are listed in parentheses. EMG, electromyogram; SCL, skin conductance level; $H R$, heart rate; SBP, systolic blood pressure; DBP, diastolic blood pressure.

${ }^{a}$ Comparisons were assessed by $t$-tests.

${ }^{\mathrm{b}}$ Comparisons were assessed by Mann-Whitney's $U$-test.

*Differential score is significantly different from 0 at $p<.05$; ${ }^{* * *}$ differential score is significantly different from 0 at $p<.001$. 
between younger and older adults is marginally significant for SBP recovery ( $t$ $(55)=-1.95, p=.06)$, but not for HR recovery, $(t(55)=-1.50, p=.14)$. No other significant difference between age groups was found.

\section{Expressive suppression}

As illustrated in Table 4, younger adults displayed lesser EMG zygomaticus major activity under the suppression condition $(t(34)=-3.07, p=.005$. The pattern of facial expressivity was similar in older adults than in younger adults but did not reach statistical significance $(t(35)=-1.75, p=.09)$. We also found that older adults looked significantly more toward cartoons' picture $(t(35)=2.27, p=.03$ ) and less toward cartoons' caption ( $t$ $(35)=-2.59, p=.01)$ compared with the simply watch condition but that younger adults did not $(t(35)=-.71, p=.48$ for cartoons' caption and $t(35)=1.77, p=.09$ for cartoons picture). Age group comparisons indicated that the difference between younger and older adults almost reached statistical significance for the gaze behavior toward cartoons' picture ( $p=.07$, Mann-Whitney $U=477$ ). No other significant difference between age groups was found.

\section{Discussion}

Despite the growing number of studies on age-related differences in the ability to regulate negative emotion (Kunzmann et al., 2005; Magai et al., 2006; Opitz et al., 2012; Phillips et al., 2008; Shiota \& Levenson, 2009; Vieillard et al., 2015; Winecoff et al., 2011), little is known about the way younger and older people can dampen or strengthen their positive emotional expression in response to humorous stimuli. This is a question of interest because it has been repeatedly shown that in comparison with younger adults, older adults favored positive over negative stimuli in cognitive processing (Reed \& Carstensen, 2012; Reed et al., 2014). This raises questions about the possibility that older adults would spontaneously react to or would implement expressive regulation of positive experience differently than their younger counterparts. The current study investigated the affective, expressive, physiological, and gaze behavior consequences of spontaneous responses to funny cartoons and expressive regulation (amplification/suppression) of mirth they elicit. There were five main findings.

First, regarding the spontaneous responses to humor, no age-related difference in the affective, physiological, and gaze behavior consequences was found. When faced with humorous cartoons, both younger and older adults reported to be more amused, showed higher physiological arousal, looked more toward the cartoons' captions, and less toward the cartoons' pictures. This later finding underlines that, whatever the age group, participants need to have a good understanding of the subtitles (i.e., caption) to appreciate the humorous cartoons.

The current findings give evidence for an age-related difference in expressive behavior. While previous works showed that the spontaneous facial expressiveness of older adults were comparable with those found in younger adults when they were asked to relive emotional events eliciting basic emotions (Levenson, Carstensen, Friesen, \& Ekman, 1991) or when they were instructed to watch sad or amusing film clips (Tsai, Levenson, \& Carstensen, 2000), our results indicated that older adults showed lower EMG zygomaticus major activity than their younger counterparts. Thus, they do not yield evidence for a 
positivity bias through this index. One possible explanation would be that older adults displayed lesser amusement simply because they had a little understanding of humorous stimuli. Our data did not corroborate this view. They showed that older adults had a mean score of understanding that was higher (6.7) than the median value (4.5), meaning that they had a good understanding of the humorous material. Therefore, the hypothesis of a decline in the cognitive processing of the humorous materiel cannot account for the decrease of spontaneous facial expression in older adults. Another explanation would be that the participants' facial expressions have not been analyzed in a similar way between previous works and the current study. Previous works have been based on the use of the Facial Action Coding System (Ekman, Friesen, \& Hager, 1978), whereas we indexed the facial expressivity with the measurement of the facial EMG activity. It is not surprising that this latter measure of facial activity was more accurate to capture effects of age than a measure based on ratings of blind judges assigning a score of expressivity. In agreement with more earlier studies (Malatesta \& Izard, 1984; Malatesta, Izard, Culver, \& Nicolich, 1987), we suspect that the age-related effect we found on the spontaneous facial expression of mirth was due to structural changes in the face of older adults. This raises the question whether the expressive facial cue is the best index to capture a positivity bias in older adults. Future investigations should provide a better understanding of how and to what extent these structural changes make the older adults' expression less patent than in younger adults.

Our results showed no significant age difference in the ability to implement the expressive amplification and suppression in response to humorous stimuli. These findings extend and corroborate previous results giving empirical evidence for intact use of expressive regulation of negative emotions (Kunzmann et al., 2005; Magai et al., 2006; Vieillard et al., 2015). At the same time, and given that we did not find that older adults were more efficient to amplify their positive expression (and experience), current findings are not in agreement with the hypothesis of a positivity bias in aging.

While we found that the exaggeration of the expression of mirth was accompanied by a greater physiological activity in younger adults, no statistically significant change was observed in older adults. Although our experiment was not designed to specify whether this increase observed in younger adults would mirror the physiological cost of the expressive amplification or whether it would sign a stronger experience of mirth, current findings suggest that compared to the younger adults, the older adults show a decrease in cardiovascular reactivity that might reflect a disconnection between the intentional behavioral expression and the internal bodily response. This is in line with previous data showing that the reduction in autonomic responses in older adults when processing emotional stimuli was associated with an intense subjective experience of emotions (Levenson et al., 1991) and a well-preserved ability to express them (Tsai et al., 2000). More generally, this supports the hypothesis of a weakening of mind-body connections with age (Mendes, 2010). According to this view, the diminished perception of internal changes in the body observed in aging (Khalsa, Rudrauf, \& Tranel, 2009) would make older adults more susceptible to the environmental cues which could impact the way they perceive and experience emotions. As yet, too little is known about how the age-related physiological changes may shape emotional experience and behavior. Further research is needed to shed more light on this issue.

Although no statistically significant age difference was found under suppression instruction, our results indicated that older adults had more difficulty than their younger counterparts to implement expressive suppression relative to their baseline 
responding. We conjecture that they were less able to suppress their expression of mirth precisely because the latter was already appeared as reduced under the condition of spontaneous response. As mentioned earlier, this might reflect structural changes in older adults' face like a reduction in flexibility of muscle tissue. As predicted, our data indicated that when they were instructed to suppress their expression, older adults, but not younger adults, looked more toward the cartoons' pictures and less toward the cartoons' captions. This suggests that to implement the expressive suppression, older adults used an avoidance strategy involving a redirection of their attention away from the area that is a prerequisite to fully understand of humorous cartoons. Then, when they were instructed to suppress their emotional expression of mirth, older adults prefer to disengage their visual attention from the area eliciting positive responses. Such pattern of results does not advocate the idea that the positivity effect in aging might lead older people to have more difficulties to divert their attention from positive information.

Overall, the current findings show that as getting older, people display a lesser spontaneous expression of mirth but show a spared voluntary expressive regulation of that emotion. Nevertheless, the older adults' abilities to amplify or suppress their amusement have different consequences for physiological and behavioral responses. Those consequences demonstrated that when instructed to exaggerate their expression, older adults show a disconnection between what they express and what they feel while when instructed to inhibit it (i.e., when the inhibition control skill is required), older adults use a less costly strategy of redirection of their attention away from the source of mirth. Importantly, the current data indicate that the older adults' emotional responses to humorous cartoons are not driven by a preference for positive stimuli in comparison with younger adults. Hence, future research must more fully explore whether the positivity bias and the reduction of negativity bias, both considered as the cue of the positivity effect, are really the two facets of the same coin.

\section{Acknowledgment}

We are grateful to Margaux Guetton and Jonathan Harm for their help in testing the participants.

\section{Disclosure statement}

No potential conflict of interest was reported by the authors.

\section{Funding}

This work was supported by a research grant EMCO program (ANR 11 EMCO 003 01) to Sandrine Vieillard.

\section{References}

Beck, A. T, Steer, R. A, Ball, R, \& Ranieri, W. (1996). Comparison of beck depression inventories-ia and-ii in psychiatric outpatients. Journal Of Personality Assessment, 67(3), 588-597. doi: 10.1207/ s15327752jpa6703_13 
Carstensen, L. L., Turan, B., Scheibe, S., Ram, N., Ersner-Hershfield, H., Samanez-Larkin, G. R., ... Nesselroade, J. R. (2011). Emotional experience improves with age: Evidence based on over 10 years of experience sampling. Psychology and Aging, 26(1), 21-33. doi:10.1037/a0021285

Charles, S. T, \& Carstensen, L. L. (2009). Socioemotional selectivity theory. In (Eds.), Encyclopedia of human relationships (pp. 1578-1581). Thousand Oaks, CA: Sage Publications.

Charles, S. T., Mather, M., \& Carstensen, L. L. (2003). Aging and emotional memory: The forgettable nature of negative images for older adults. Journal of Experimental Psychology. General, 132(2), 310-324. doi:10.1037/0096-3445.132.2.310

Charles, S. T., Reynolds, C. A., \& Gatz, M. (2001). Age-related differences and change in positive and negative affect over 23 years. Journal of Personality and Social Psychology, 80(1), 136-151. doi:10.1037/0022-3514.80.1.136

Consedine, N. S., \& Magai, C. (2006). Emotion development in adulthood: A developmental functionalist review and critique. In C. Hoare (ed.), The Oxford handbook of adult development and learning (pp. 209-244). New York: Oxford University Press.

Ekman, P., Friesen, W. V., \& Hager, J. C. (1978). Facial action coding system (FACS). Palo Alto, California: Consulting.

Folstein, M. F, Folstein, S. E, \& McHugh, P. R. (1975). Mini-mental state. A Practical Method For Grading The Cognitive State Of Patients For The Clinician. Journal Of Psychiatric Research, 12(3), 189-198. doi:10.1016/0022-3956(75)90026-6

Fölster, M., Hess, U., \& Werheid, K. (2014). Facial age affects emotional expression decoding. Frontiers in Psychology, 5, 30. doi:10.3389/fpsyg.2014.00030

Giuliani, N. R., McRae, K., \& Gross, J. J. (2008). The up- and down-regulation of amusement: Experiential, behavioral, and autonomic consequences. Emotion (Washington, D.C.), 8(5), 714719. doi:10.1037/a0013236

Gross, J. J. (2014). The handbook of emotion regulation. New York: The Guilford Press.

Gross, J. J., Carstensen, L. L., Pasupathi, M., Tsai, J., Skorpen, C. G., \& Hsu, A. Y. (1997). Emotion and aging: Experience, expression, and control. Psychology and Aging, 12(4), 590-599. doi:10.1037/ 0882-7974.12.4.590

Gross, J. J, \& John, O. P. (2003). Individual differences in two emotion regulation processes: implications for affect, relationships, and well-being. Journal Of Personality And Social Psychology, 85(2), 348-362. doi:10.1037/0022-3514.85.2.348

Gross, J. J., \& Thompson, R. A. (2007). Emotion Regulation: Conceptual Foundations. In J. J.Gross (Ed.), Handbook of emotion regulation (pp. 3-24). New York, NY, US: Guilford Press

Gross, J.J, \& John, O.P. (1997). Revealing feelings: facets of emotional expressivity in self-reports, peer ratings, and behavior. Journal Of Personality And Socialpsychology, 72, 435-448. doi: 10.1037/0022-3514.72.2.435

Harm, J., Vieillard, S., \& Didierjean, A. (2014). Using humour as an extrinsic source of emotion regulation in young and older adults. Quarterly Journal of Experimental Psychology (2006), 67(10), 1895-1909. doi:10.1080/17470218.2013.873474

Hasher, L., \& Zacks, R. T. (1988). Working memory, comprehension, and aging: A review and a new view. Psychology of Learning and Motivation, 193-225. doi:10.1016/S0079-7421(08)60041-9

Henry, J. D., Rendell, P. G., Scicluna, A., Jackson, M., \& Phillips, L. H. (2009). Emotion experience, expression, and regulation in Alzheimer's disease. Psychology and Aging, 24(1), 252-257. doi:10.1037/a0014001

Khalsa, S. S., Rudrauf, D., \& Tranel, D. (2009). Interoceptive awareness declines with age. Psychophysiology, 46(6), 1130-1136. doi:10.1111/j.1469-8986.2009.00859.x

Kunzmann, U., Kupperbusch, C. S., \& Levenson, R. W. (2005). Behavioral inhibition and amplification during emotional arousal: A comparison of two age groups. Psychology and Aging, 20(1), 144158. doi:10.1037/0882-7974.20.1.144

Larson, G. (1985). Valley of the far side. Kansas City, MO: Universal Press.

Larson, G. (1987). The far side observer. Kansas City, MO: Universal Press.

Larson, G. (1988). Night of the crash-test dummies. Kansas City, MO: Universal Press.

Lawton, M. P. (2001). Emotion in later life. Current Directions in Psychological Science, 10(4), 120 123. doi:10.1111/1467-8721.00130 
Levenson, R. W., Carstensen, L. L., Friesen, W. V., \& Ekman, P. (1991). Emotion, physiology, and expression in old age. Psychology and Aging, 6(1), 28-35. doi:10.1037/0882-7974.6.1.28

Magai, C., Consedine, N. S., Krivoshekova, Y. S., Kudadjie-Gyamfi, E., \& McPherson, R. (2006). Emotion experience and expression across the adult life span: Insights from a multimodal assessment study. Psychology and Aging, 21(2), 303-317.

Malatesta, C. Z., \& Izard, C. E. (1984). The facial expression of emotion: Young, middle-aged, and older adult expressions. In: C. Z. Malatesta \& C. E. Izard (Eds.), Emotion in adult development (pp. 253-273). London: Sage Publications.

Malatesta, C. Z., Izard, C. E., Culver, C., \& Nicolich, M. (1987). Emotion communication skills in young, middle-aged, and older women. Psychology and Aging, 2(2), 193-203. doi:10.1037/0882-7974.2.2.193

Martin, R. A. (2007). The psychology of humor: An integrative approach. Amsterdam: Elsevier Academic Press.

Martins, B., Sheppes, G., Gross, J. J., \& Mather, M. (2016). Age differences in emotion regulation choice: Older adults use distraction less than younger adults in high-intensity positive contexts. The Journals of Gerontology. Series B, Psychological Sciences and Social Sciences. doi:10.1093/geronb/gbw028

Mather, M., Canli, T., English, T., Whitfield, S., Wais, P., Ochsner, K., ... Carstensen, L. L. (2004). Amygdala responses to emotionally valenced stimuli in older and younger adults. Psychological Science, 15(4), 259-263. doi:10.1111/j.0956-7976.2004.00662.x

Mather, M., \& Carstensen, L. L. (2005). Aging and motivated cognition: The positivity effect in attention and memory. Trends in Cognitive Sciences, 9(10), 496-502. doi:10.1016/j.tics.2005.08.005

Mendes, W. B. (2010). Weakened links between mind and body in older age: The case for maturational dualism in the experience of emotion. Emotion Review, 2, 240-244. doi:10.1177/ 1754073910364149

Mikels, J. A., Larkin, G. R., Reuter-Lorenz, P. A., \& Carstensen, L. L. (2005). Divergent trajectories in the aging mind: Changes in working memory for affective versus visual information with age. Psychology and Aging, 20(4), 542-553. doi:10.1037/0882-7974.20.4.542

Mroczek, D. K., \& Kolarz, C. M. (1998). The effect of age on positive and negative affect: A developmental perspective on happiness. Journal of Personality and Social Psychology, 75(5), 1333-1349. doi:10.1037/0022-3514.75.5.1333

Opitz, P. C., Rauch, L. C., Terry, D. P., \& Urry, H. L. (2012). Prefrontal mediation of age differences in cognitive reappraisal. Neurobiology of Aging, 33(4), 645-655. doi:10.1016/j.neurobiolaging.2010.06.004

Phillips, L. H., Henry, J. D., Hosie, J. A., \& Milne, A. B. (2008). Effective regulation of the experience and expression of negative affect in old age. The Journals of Gerontology. Series B, Psychological Sciences and Social Sciences, 63(3), P138-145. doi:10.1093/geronb/63.3.P138

Plaisant, O. (2010). Validation par analyse factorielle du big five inventory français (bfi-fr) analyse convergente avec le neo-pi-r. Annales Médico-psychologiques, Revue Psychiatrique, 168, 97-102. doi: https://doi.org/10.1016/j.amp.2009.09.003

Raven, J, Raven, J. C, \& Court, J. H. (2003). Manual for raven's progressive matrices and vocabulary scales. In Section 1. San Antonio, TX: Harcourt Assessment.

Reed, A. E., \& Carstensen, L. L. (2012). The theory behind the age-related positivity effect. Frontiers in Psychology, 3, 339. doi:10.3389/fpsyg.2012.00339

Reed, A. E., Chan, L., \& Mikels, J. A. (2014). Meta-analysis of the age-related positivity effect: Age differences in preferences for positive over negative information. Psychology and Aging, 29(1), 1-15. doi:10.1037/a0035194

Samson, A. C., \& Gross, J. J. (2012). Humour as emotion regulation: The differential consequences of negative versus positive humour. Cognition \& Emotion, 26(2), 375-384. doi:10.1080/ 02699931.2011 .585069

Schmidt, S. R. (2002). The humour effect: Differential processing and privileged retrieval. Memory, 10(2), 127-138. doi:10.1080/09658210143000263

Schneider, W., Eschman, A., \& Zuccolotto, A. (2002). E-Prime (Version 2.0). Pittsburgh, PA: Psychology Software Tools Inc.

Shammi, P., \& Stuss, D. T. (2003). The effects of normal aging on humor appreciation. Journal of the International Neuropsychological Society : JINS, 9(6), 855-863. doi:10.1017/S135561770396005X 
Shiota, M. N., \& Levenson, R. W. (2009). Effects of aging on experimentally instructed detached reappraisal, positive reappraisal, and emotional behavior suppression. Psychology and Aging, 24 (4), 890-900. doi:10.1037/a0017896

Spielberger, C.D, Gorsuch, R.L, Lushene, R, Vagg, P.R, \& Jacobs, G.A. (1983). Manual for the statetrait anxiety inventory. Palo Alto:Consulting Psychologists Press.

Strick, M., Holland, R. W., Van Baaren, R. B., \& Van Knippenberg, A. (2009). Finding comfort in a joke: Consolatory effects of humor through cognitive distraction. Emotion (Washington, D.C.), 9(4), 574-578. doi:10.1037/a0015951

Tassinary, L. G, Cacioppo, J. T, \& Vanman, E. J. (2007). (Ed.), The skeletomotor system: surface electromyography (3rd. pp. 267-299). New York: Cambridge University Press.

Terracciano, A., McCrae, R. R., Brant, L. J., \& Costa, P. T. J. (2005). Hierarchical linear modeling analyses of the neo-pi-r scales in the baltimore longitudinal study of aging. psychology and aging, 20(3),493-506. doi: https://doi.org/10.1037/0882-7974.20.3.493. It must be include in the references section of the paper.

Tombaugh, T. N. (2004). Trail making test a and b: normative data stratified by age and education. Archives Of Clinical Neuropsychology : The Official Journal Of The National Academy Of Neuropsychologists, 19(2), 203-214. doi: 10.1016/S0887-6177(03)00039-8

Tremblay, M.-P, Potvin, O, Belleville, S, Bier, N, Gagnon, L, Blanchet, S, \& Hudon, C. (2016). The victoria stroop test: normative data in quebec-french adults and elderly. Archives Of Clinical Neuropsychology : The Official Journal Of The National Academy Of Neuropsychologists. doi: https://doi.org/10.1093/arclin/acw029

Tsai, J. L., Levenson, R. W., \& Carstensen, L. L. (2000). Autonomic, subjective, and expressive responses to emotional films in older and younger Chinese Americans and European Americans. Psychology and Aging, 15(4), 684-693. doi:10.1037/0882-7974.15.4.684

Vieillard, S., \& Bigand, E. (2014). Distinct effects of positive and negative music on older adults' auditory target identification performances. Quarterly Journal of Experimental Psychology (2006), 67(11), 2225-2238. doi:10.1080/17470218.2014.914548

Vieillard, S., Harm, J., \& Bigand, E. (2015). Expressive suppression and enhancement during musicelicited emotions in younger and older adults. Frontiers in Aging Neuroscience, 7, 11. doi:10.3389/fnagi.2015.00011

Watson, D, \& Clark, L. A. (1994). The panas-x: manual for the positive and negative affect scheduleexpanded form. Ames: The University of lowa.

Wechsler, D. (1997). Wechsler Adult Intelligence Scale-3rd Edition (WAIS-3 ${ }^{\oplus}$ ) San Antonio, TX: Harcourt Assessment

Winecoff, A., Labar, K. S., Madden, D. J., Cabeza, R., \& Huettel, S. A. (2011). Cognitive and neural contributors to emotion regulation in aging. Social Cognitive and Affective Neuroscience, 6(2), 165-176. doi:10.1093/scan/nsq030 